\title{
Combined endoclipping and argon plasma coagula- tion (APC)-daisy technique for cecal angiodysplasia
}

A 75-year-old man was referred to our clinic for evaluation of iron deficiency anemia and occult gastrointestinal bleeding. Colonoscopy showed multiple, large (7$10 \mathrm{~mm}$ ), flat, and elevated cherry-red colored vascular malformations (arteriovenous malformations [AVM]) in a fernlike pattern in the cecum. After thorough inspection of the lesions we were able to identify the feeding vessel. We placed endoclips $1-2 \mathrm{~cm}$ proximal to the AVM and waited for the lesion to demonstrate signs of hypoperfusion (i.e., ischemia) ( Fig. 1). We then treated the AVM in the standard way with argon plasma coagulation (APC; ERBE ICC 200, power settings: $40 \mathrm{~W}$ and gas flow 2L; Erbe, Tuebingen, Germany), starting first around the malformation and later targeting the center of the lesion ( $\mathrm{Fig} .2$ ). In order to minimize heat damage to the deeper tissue, pulses of $1-2$ seconds duration were repeatedly applied to destroy the blood vessels. During APC, careful attention was paid to avoid application of current to the endoclip, as this could have resulted in perforation. Using this technique, we encountered far less bleeding in comparison with previous experiences of treating AVM without obliteration of the feeding vessel ( $\bullet$ Fig. 3 ). Angioectasias are defined as pathologically dilated submucosal veins with overlying ectasia of the mucosal venules and capillaries [1]. Because of the presence of arteriovenous communications in some angioectasias, the lesions are identified as AVM. Colonic AVM tend to be solitary and large in size [2]. Endoscopic ablation is commonly utilized to treat vascular lesions throughout the gastrointestinal tract [3]. It includes contact coagulation methods such as monopolar/bipolar probes or heat probe, and noncontact methods, e.g., APC, and occasionally endoclipping on its own [3-5]. We decided to apply endoclips prior to thermal ablation of the AVM itself to minimize tissue damage from APC and its attendant complications, such as bleeding, which may also decrease the ablative efficacy of APC because of dissipation of energy. In sum, in this case report we have presented a new concept of combining endoscopic techniques, which we hope will prove efficacious in future studies on treatment of colonic AVM.

\section{Endoscopy_UCTN_Code_TTT_1AQ_2AZ}

Competing interests: None

\section{Ivan Jovanovic ${ }^{1}$, Aleksandar Knezevic ${ }^{2}$}

${ }^{1}$ Clinic for Gastroenterology and Hepatology, Clinical Center of Serbia, Serbia Medical School, University of Belgrade, Belgrade, Serbia

${ }^{2}$ Clinic for Gastroenterology and Hepatology, Clinical Center of Novi Sad, Serbia

\section{References}

1 Regula J, Wronska E, Pachlewski J. Vascular lesions of the gastrointestinal tract. Best Pract Res Clin Gastroenterol 2008; 22: 313-328

2 Bollinger E, Raines D, Saitta P. Distribution of bleeding gastrointestinal angioectasias. World J Gastroenterol 2012; 18: 6235-6239

3 Kwan V, Bourke MJ, Williams SJ et al. Argon plasma coagulation in the management of symptomatic gastrointestinal vascular lesions: experience in 100 consecutive patients with long-term follow-up. Am J Gastroenterol 2006; 101: 58-63

4 Takahashi N, Tanabe K, Yoshitomi $\mathrm{H}$ et al. Successful endoscopic clipping for bleeding from colonic angiodysplasia in a case of Heyde syndrome. Med Sci Monit 2010; 16: 107-109

5 Suzuki N, Arebi N, Saunders B. A novel method of treating colonic angiodysplasia. Gastrointest Endosc 2006; 64: 425-426

\section{Bibliography}

Dol http://dx.doi.org/

10.1055/s-0033-1344826

Endoscopy 2013; 45: E384

(c) Georg Thieme Verlag KG

Stuttgart · New York

ISSN 0013-726X

\section{Corresponding author}

Ivan Jovanovic

Clinic for Gastroenterology and Hepatology

Clinical Center of Serbia

Belgrade

Koste Todorovica 2

11000 Beograd

Serbia

Fax: +381-11-3615587

ivangastro@beotel.rs

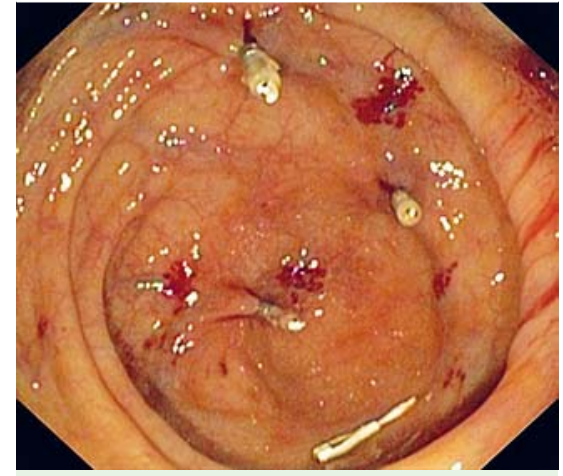

Fig. 1 Endoclips placed $1-2 \mathrm{~cm}$ proximal to colonic arteriovenous malformations (AVM) in a 75-year-old man. Following this, we waited for the lesion to demonstrate signs of hypoperfusion.

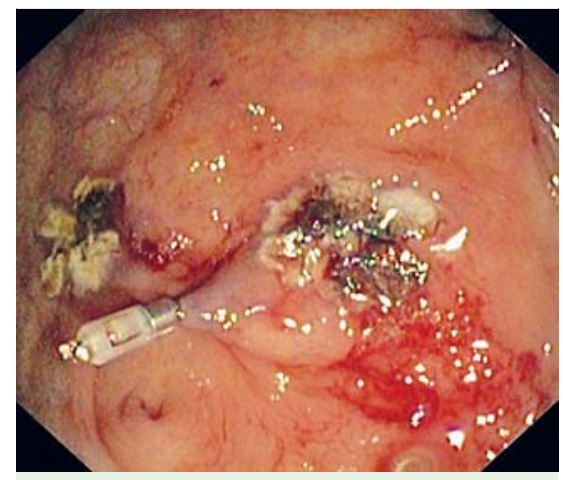

Fig. 2 The main arteriovenous malformation (AVM) was treated using argon plasma coagulation (APC).

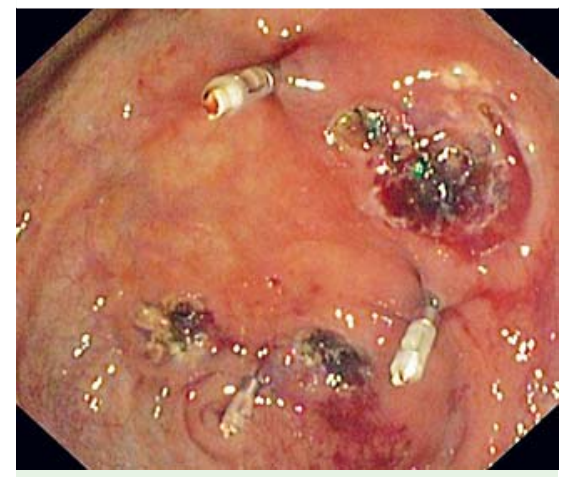

Fig. 3 The combination of clipping and argon plasma coagulation (APC) may result in less bleeding, as the main feeding vessel of the arteriovenous malformation (AVM) is obliterated by the clip. 